\title{
Codal Requirements Using Capacity Design Philosophy, and Their Applications in the Design of Steel Structures in Seismic Zones
}

\author{
Muhammad Tayyab Naqash, Ayed Alluqmani \\ Department of Civil Engineering, Islamic University in Madinah, Madina Almunaworah, KSA \\ Email: engr.tayyabnaqash@gmail.com, tayyab@iu.edu.sa, dr.ayed@iu.edu.sa, eng.ayed@hotmail.com
}

How to cite this paper: Naqash, M.T. and Alluqmani, A. (2018) Codal Requirements Using Capacity Design Philosophy, and Their Applications in the Design of Steel Structures in Seismic Zones. Open Journal of Earthquake Research, 7, 88-107. https://doi.org/10.4236/ojer.2018.72006

Received: April 16, 2018

Accepted: May 27, 2018

Published: May 30, 2018

Copyright $\odot 2018$ by authors and Scientific Research Publishing Inc. This work is licensed under the Creative Commons Attribution International License (CC BY 4.0).

http://creativecommons.org/licenses/by/4.0/

c. (i) Open Access

\begin{abstract}
The use of steel structures in the developing countries is limited in spite of its better performance in the case of seismic events due to its high ductility. Although steel structures behave well under seismic excitation, nevertheless the use of structural steel is limiting these days. This paper aims to address various parameters related to the capacity design approach involved in the seismic design of conventional steel structures. Few cases of the early steel structures construction such as bridges in Pakistan are briefly described. Philosophies based on the capacity design approach and the importance of conventional steel lateral load resisting systems with their global mechanisms are provided. The design procedures of Eurocode $\mathbf{8}$ for Steel Moment resisting frames, Concentric cross braced frames and Eccentric braced frames are given and illustrated. It is believed that the paper will contribute and will be helpful for the designers, researchers and academicians involve in the study of lateral load resisting systems for incorporating in the design process. Since synopsis tables are provided, therefore this will allow a clear understanding of the capacity design approach for different lateral load resisting systems.
\end{abstract}

\section{Keywords}

Moment Resisting Frames, Concentric Cross Braced Frames, Eccentric Braced Frames, Behaviour Factor, Eurocode 8, Seismic Code in Pakistan

\section{Introduction}

The philosophies of seismic design codes rely on the inherent capability of structures to undergo inelastic deformation. Since steel is strong, light weight, ductile and tough material hence believed to be capable of dissipating extensive 
energy through yielding when stressed in the inelastic range, these are exactly the properties desired for seismic resistance. In fact, other construction materials rely on these basic properties of steel to assist them in attaining adequate seismic resistance. Throughout the relatively brief history, structural steel buildings have been among the best performing structural systems. Prior to January 1994 when previously unanticipated connection failures were discovered in some buildings following the Northridge earthquake (M 6.7), many engineers mistakenly regarded such structures as nearly earthquake-proof. A year later, the Kobe earthquake (M 6.9) caused collapse of 50 steel buildings confirming the potential vulnerability of these structures. This experiences notwithstanding structural steel buildings if properly designed can provide outstanding earthquake performance. This paper introduces the general concepts of conventional steel structures that should be followed during analyzing and designing when dealing with earthquake forces. The trend of design of steel structures is highly encouraging in $\mathrm{Pa}$ kistan as it is a high seismic region; the October 2005 earthquake is a clear example. Nevertheless, less work has been done on the seismic design of steel structures compared to other materials such as masonry, reinforce concrete and timber etc. It is to be noted here that Building Code of Pakistan (BCP) [1] with the aid of "UBC 97" [2] is the only reference Code that is adopted in the Country and is recommended by Earthquake Reconstruction and Rehabilitation Authority. The seismic zones as mentioned in Table 1 defined by this Code are compatible with the zonation map of Pakistan. The seismic zones as shown in Figure 1 assumed by BCP are mentioned in Table 1 considering five seismic zones. Since it is believed and recommended by the design community that steel structures perform well during earthquake, therefore, it is of high interest to the possibilities of applying more advanced design procedures in Pakistan. Seismic design procedures, accurate seismic zoning, and related earthquake design Codes are the topics of high concern in Pakistan. Some major past earthquakes that hit the country with fatalities are mentioned below [3] [4].

- In 1935 at 05:30-Quetta, Pakistan-M 7.5 Fatalities 30,000.

- In 1945 at 11:27-Makran Coast, Pakistan-M 8.0 Fatalities 4000.

- In 1974 at 12:28-Northern Pakistan-M 6.2 Fatalities 5300.

- In 2005 at 10:08-Kashmir Pakistan-M 7.6 Fatalities 86,000.

- In 2008 at 10:28-Pakistan-M 6.4 Fatalities 166.

- In 2011 at 01:18-Pakistan-M 7.2 Fatalities 3.

\section{Steel Structures in Pakistan}

Since Pakistan is a developing Country the aforementioned earthquakes strongly influenced the infrastructure in the corresponding areas and caused huge number of casualties as collapse and high damages were depicted within the building structures. It is believed that steel structures performed well during the past earthquakes, most of these structures are bridges or structures that were constructed to serve railways such as railway stations etc. In 1947 before the 
Table 1. Seismic zones of Pakistan.

\begin{tabular}{cccccc}
\hline S. No & $\begin{array}{c}\text { Seismic } \\
\text { Zones }\end{array}$ & Peak Ground Acceleration & Hazard Level & Damage Intensity & Damage Effect \\
\hline 1 & 1 & 0.05 to $0.08 \mathrm{~g}$ & Low & Negligible & Low \\
2 & $2 \mathrm{~A}$ & 0.08 to $0.16 \mathrm{~g}$ & Moderate & Minor & Medium \\
3 & $2 \mathrm{~B}$ & 0.16 to $0.24 \mathrm{~g}$ & & Moderate & \\
4 & 3 & 0.24 to $0.32 \mathrm{~g}$ & Large & Sever & High \\
5 & 4 & $>0.32 \mathrm{~g}$ & Sever & Collapse & Huge \\
\hline
\end{tabular}

NOTE: Where "g" is the acceleration due to gravity. The acceleration values are for Medium hard rock $\left(\mathrm{S}_{\mathrm{B}}\right)$ site condition with shear wave velocity $\left(v_{s}\right)$ of $760 \mathrm{~m} / \mathrm{sec}$.

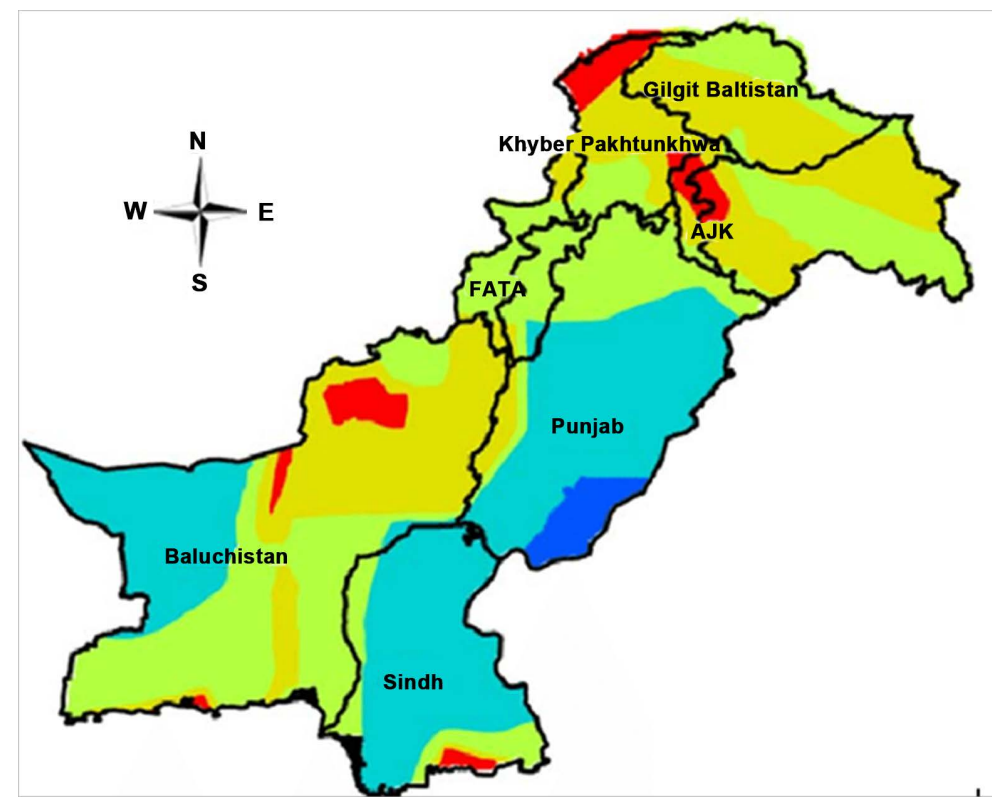

Figure 1. Seismic zoning map of pakistan.

independence of Pakistan from the British steel Moment Resisting Frames achieve good performance under seismic events. After the 1931 Mach earthquake some structures (see Figure 2) were designed according to the recommendation provided by Eng. Kumar which were tested by the 1935 Quetta earthquake and evidenced that even a modest design of steel structures saved lives in such earthquakes. These frames resisted the 1935 Quetta earthquake without significant damages [5] [6].

Pakistan located in Southeast Asia; composed of number of rivers therefore bridges represent a sort of common connection for different regions and presents a vital role in the transportation such as railways, highways as well for pedestrians. Before the independence many bridges that are constructed in the British Era are constructed of steel using riveted trusses having built-up members (mostly back to back channels). For examples the Jhelum Bridge (Figure 3) crosses the Jhelum River is composed of iron trusses over a long network of concrete piers. Lansdowne Bridge constructed in Sukkur-Rohri is a long 

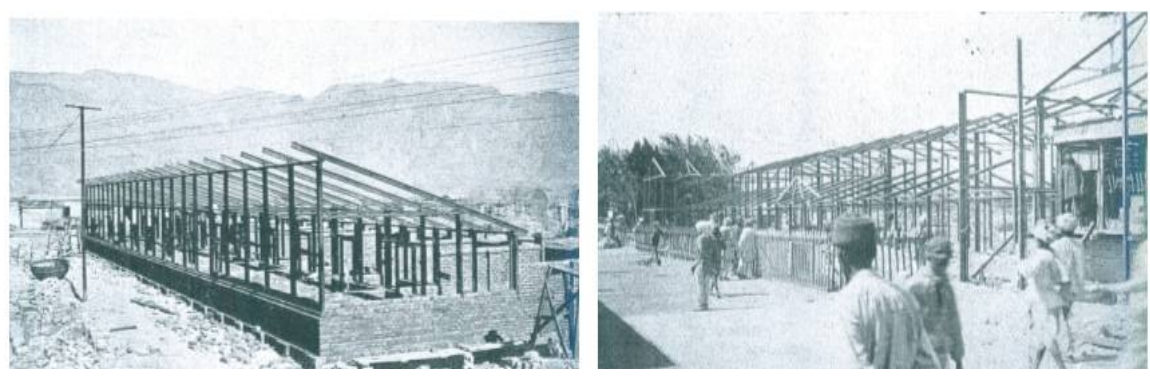

Figure 2. Undamaged steel structures tested by 1935 Quetta earthquake.

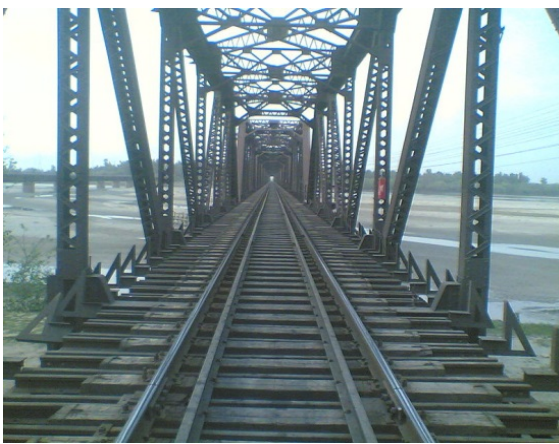

(a)

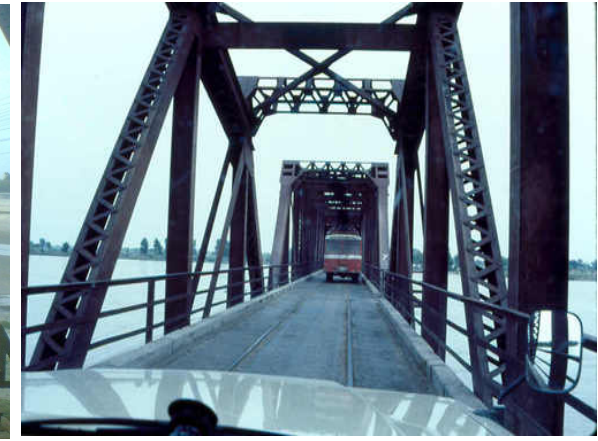

(b)

Figure 3. (a) Alexandria bridge, gujarat; (b) Old bridge over Jhelum.

single-span cantilever bridge completed in 1889. It was one of the great engineering feats of its time because the Indus River was too large to divert its waters to install piers therefore large beams cantilevered from the river side and was supported by the land on the other side. These cantilevers from both sides were joined in the middle by a system of trusses. Just $30 \mathrm{~m}$ away from this bridge the Ayub Arch stands which is an arch-pan bridge built to divert railway traffic away from the aging Lansdowne Bridge Rohri. The Attock railway bridge (Figure 4), the Alexandria Bridge in Jhelum and the Ayub arch bridge (See Figure 5) are about 50 years old whereas the Lansdowne bridge is about 100 years old located in Rohri, Sukkur. The Attock Bridge consisted of 5 spans, three are $257 \mathrm{ft}$. long and two are 312 feet long. The historical bridge (Figure 6 and Figure 7) at Malakwal-Haranpur section on river Jhelum connect the three districts of Punjab, i.e. Mandi Bahauddin, Jhelum and Sargodha at a same place.

In Pakistan, almost all the railway station are ancient such as the one of Lahore (see Figure 8), constructed in British era. Due to un-availability of data on specific structure sufficient information is not available but the authors aims to enlarge such study in future to enhance the culture of steel structure in the Country [7].

In more recent times steel structures are available in the form of telecommunication towers, electric poles, sign boards, petrol pumps etc. and rarely some industrial buildings (See Figure 9 and Figure 10). This demonstrates the poor culture of structural steel in the Country. 


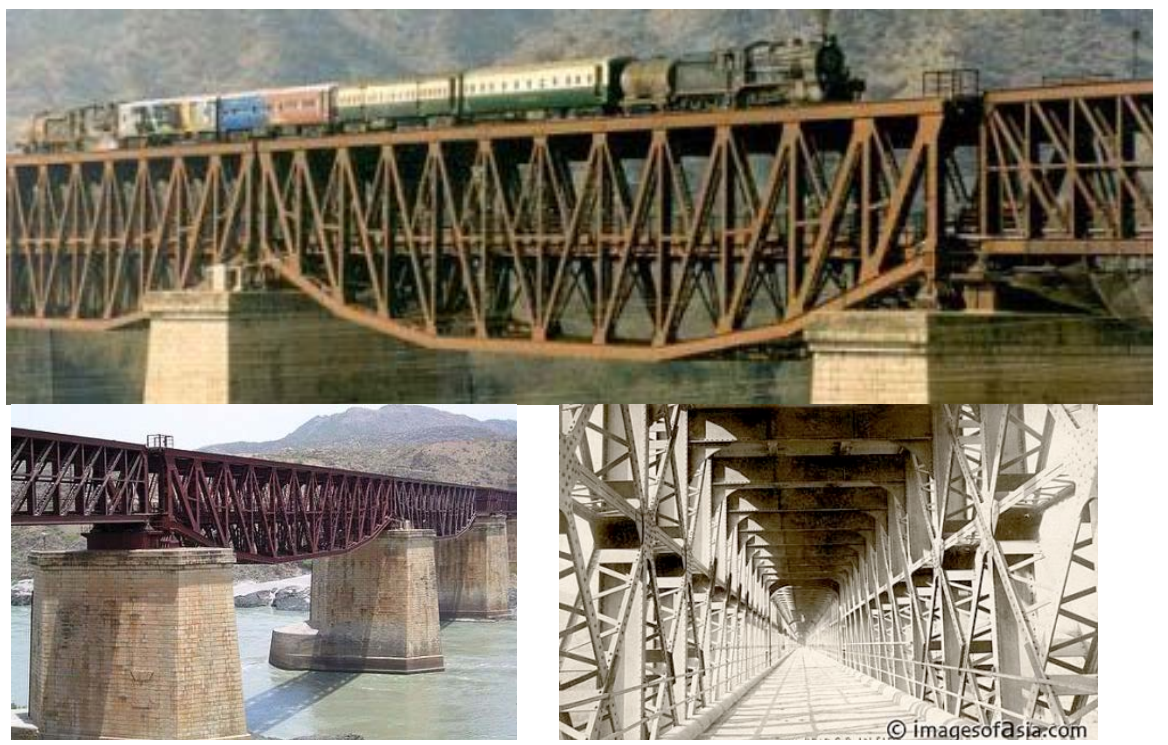

Figure 4. Attock Bridge.

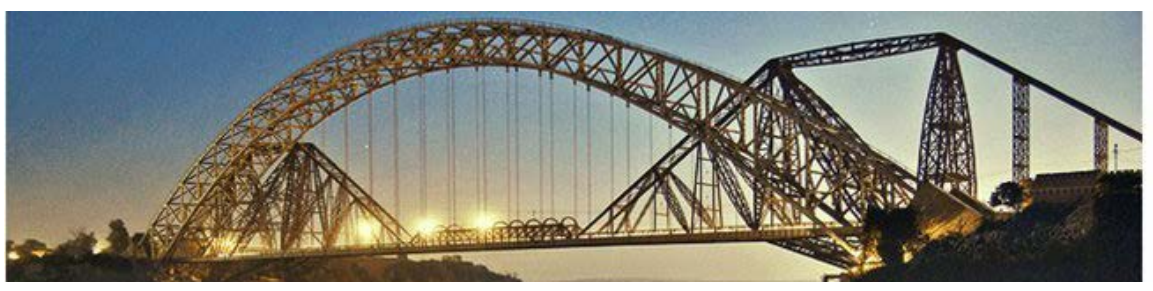

Figure 5. Lansdowne and ayub arch bridge.

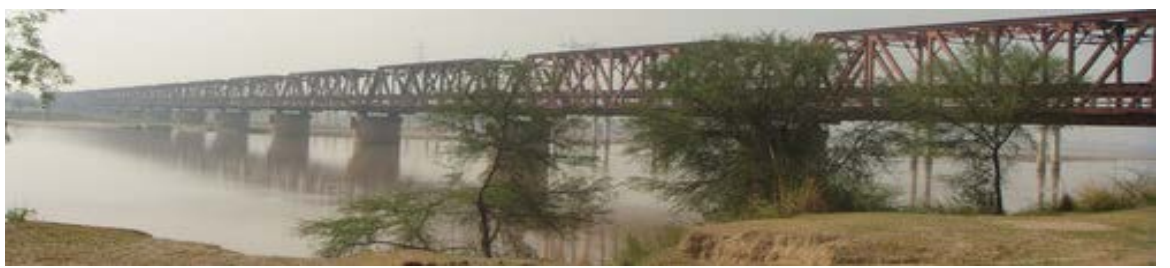

Figure 6. Historical bridge at Malakwal-Haranpur section on river Jhelum.
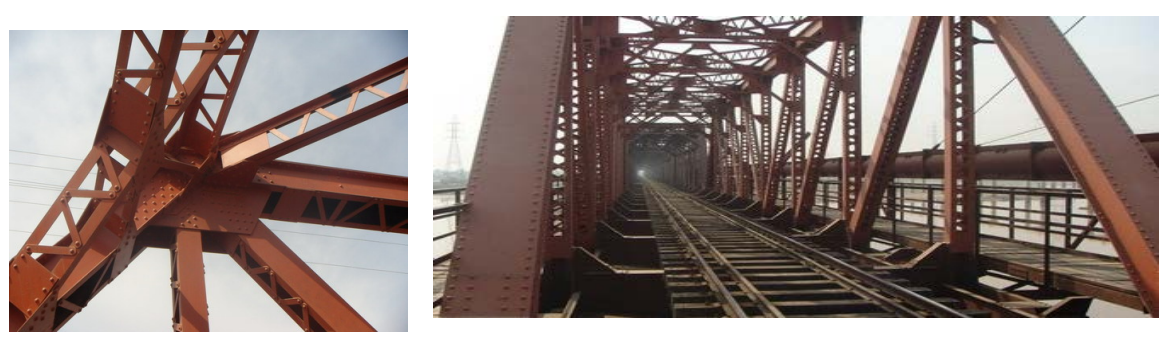

Figure 7. Victoria Bridge Historical bridge at Malakwal-Haran Pur section on river Jhelum.

\section{Parameters Used in Capacity Design Approaches}

Since steel frames are generally highly flexible, therefore they are characterized by relatively high fundamental period. Further, as it is revealed in [8] [9] for 


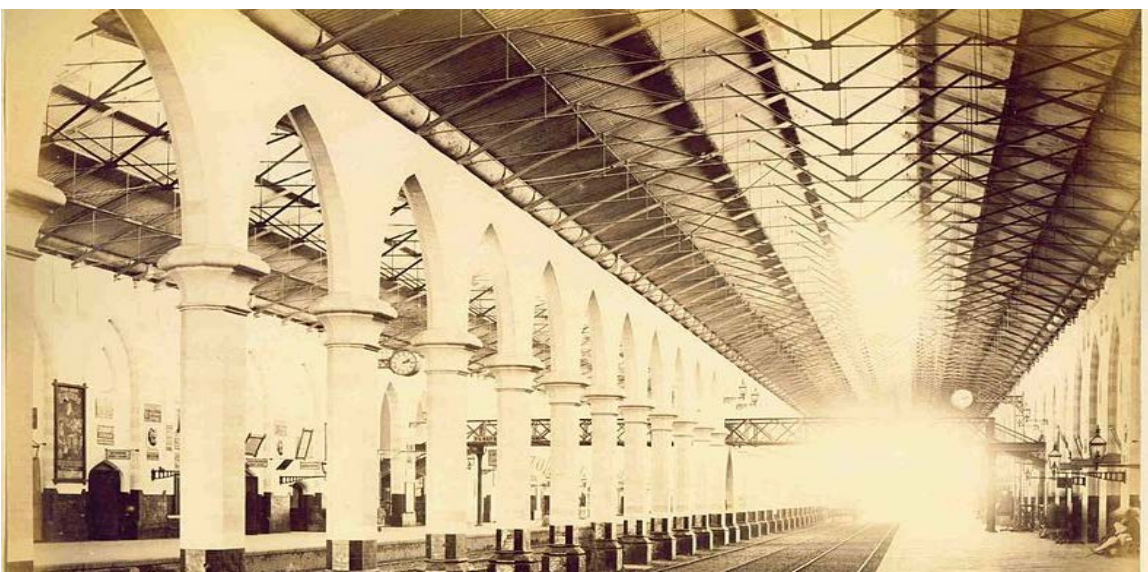

Figure 8. Lahore railway station showing the roof trusses (courtesy unknown).

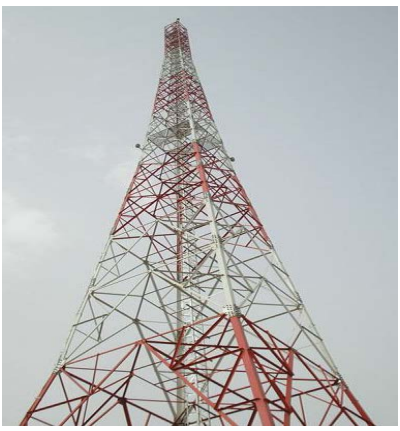

(a)

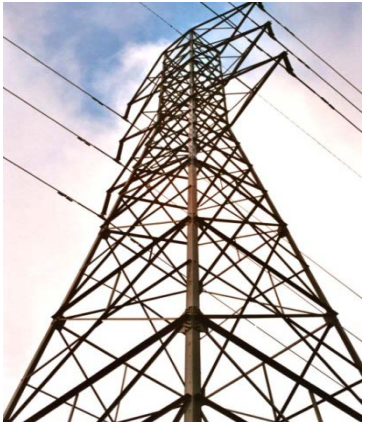

(b)

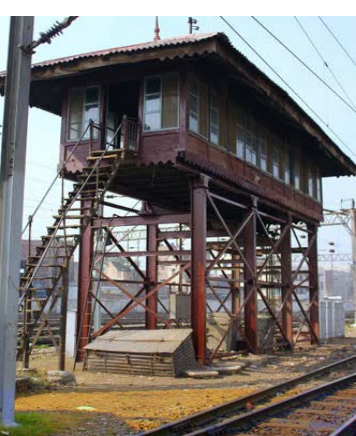

(c)

Figure 9. (a) Telecome tower; (b) Electric Transmission tower; (c) Overhead water tank.

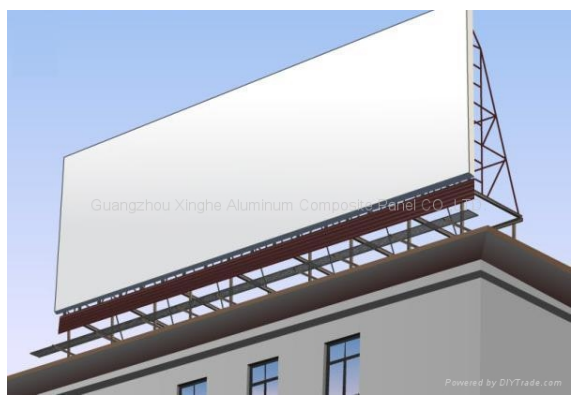

(a)

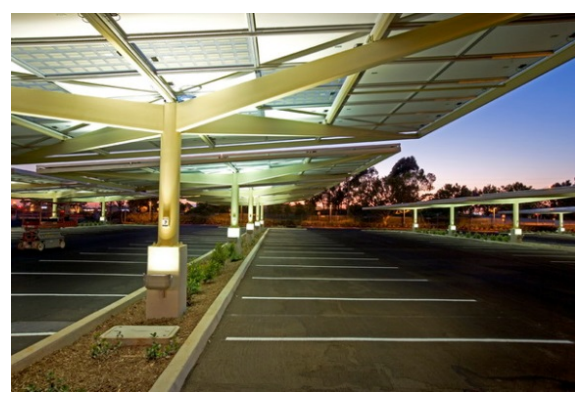

(b)

Figure 10. (left) Sign board (right) Parking shade.

medium and long period, the "equal displacement rule" implies. Therefore the main factors affecting the structural behavior under seismic excitation can be obtained from pushover analysis using the "equal displacement rules", as shown in Figure 11 and explained in the following [10] [11] [12].

Ductility reduction factor: It is the ratio of $V_{e}$ to $V_{y}$ as shown in Equation (1), it can also be termed as expected behaviour factor.

$$
q_{\mu, \rho}=\frac{V_{e}}{V_{y}}
$$




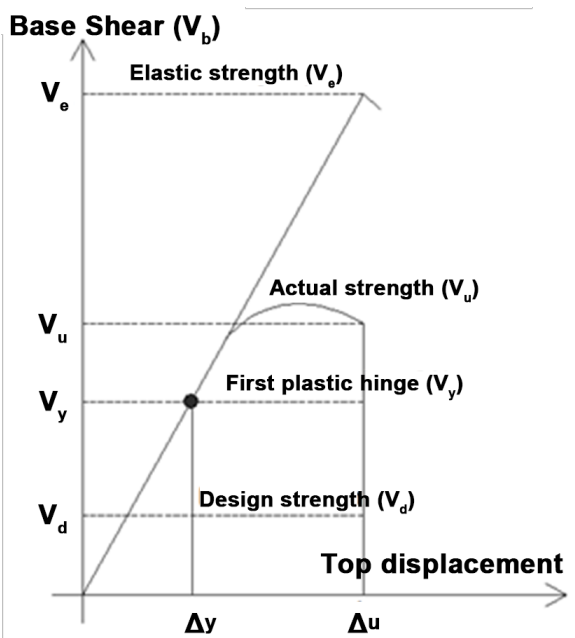

(a)

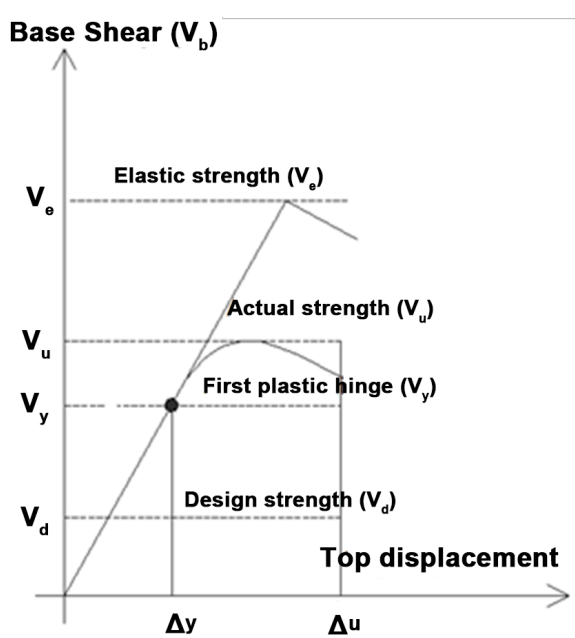

(b)

Figure 11. Common factors used in seismic Codes (a), and equal displacement approximation (b).

Redundancy factor: It is the over-strength given by the redistribution of the plastic hinges and termed as redundancy factor; it is the ratio of $V_{u}$ obtained from pushover analysis to $V_{y}$ defined by Equation (2). Redundancy exists when multiple elements must yield or fail before a complete collapse mechanism forms. Structures possessing low inherent redundancy are required to be stronger and more resistant to damage and therefore seismic design forces are amplified. Therefore, normally it is assumed that structures having larger global ductility exhibits high redundancy and vice versa.

$$
\Omega_{\rho}=\frac{V_{u}}{V_{y}}
$$

Elastic overstrength factor: It is the allowable stress reduction factor and is given by the ratio of $V_{y}$ to $V_{d}$ given by Equation (3). As an ideal scenario in the design $\Omega_{E}$ might be unity. Since the structural capacity must not be less than the design forces, $\Omega_{E}$ is always at least 1 .

$$
\Omega_{E}=\frac{V_{y}}{V_{d}}
$$

Global overstrength factor: It is given by the ratio of $V_{u}$ to $V_{\dot{d}}$ it corresponds to the product of redundancy factor and elastic overstrength, evaluated from Eq. (4).

$$
\Omega_{E, \rho}=\Omega_{E} \times \Omega_{\rho}=\left(\frac{V_{y}}{V_{d}}\right) \times\left(\frac{V_{u}}{V_{y}}\right)=\frac{V_{u}}{V_{d}}
$$

Reserve ductility: It is the ratio of $V_{e}$ to $V_{u}$ as given in Equation (5) as well from Equation (7) and Equation (8).

$$
q_{\mu}=\left(\frac{V_{e}}{V_{u}}\right)
$$


Behaviour factor: It is given by the ratio of $V_{e}$ to $V_{d}$ it is simply the product of elastic overstrength, redundancy factor and reserve ductility defined by Eq. (6).

$$
\begin{gathered}
q_{d}=\Omega_{E} \times \Omega_{\rho} \times q_{\mu}=\left(\frac{V_{y}}{V_{d}}\right) \times\left(\frac{V_{u}}{V_{y}}\right) \times\left(\frac{V_{e}}{V_{u}}\right)=\frac{V_{e}}{V_{d}} \text { or } q_{d}=\left(\frac{\Delta_{u}}{\Delta_{y}}\right) \\
q_{\mu}=\frac{V_{e}}{V_{u}}=\frac{q_{d}}{\Omega_{E, \rho}} \\
q_{\mu, \rho}=\frac{V_{e}}{V_{y}}=q_{u} \times \Omega_{\rho}
\end{gathered}
$$

\section{Lateral Load Resisting Systems}

Seismic design necessitates the combinations of deformability, strength and most importantly the ductility characteristics of a structural system. Although steel structures have the capability to resist the lateral actions by means of different Lateral Load Resisting Systems (LLRS). Nevertheless the impairing of strength with the ductility and deformability is a big challenge for the designer. Several types of earthquake resistant steel structures (some LLRS can be combined with the others) which depend on the selected load carrying mechanism can be conceived. These LLRSs have pros and cons on each other due to their characteristics such as high deformability (like MRFs), architectural constraints (like cross bracing that may restrict the opening) and geotechnical issues (for example concentration of forces on the footings). The most conventional types of earthquake resistant steel structures are: a) Rigid Frames, b) Concentric Braced Frames and c) Eccentric Braced Frames.

The main features for these systems with the design criteria with respect to Eurocode 8 [13] are summarized [14] [15] [16]. The Pakistan building code take advantage of the use of UBC 97 [2] as the definition of the seismic zones of UBC are compatible. Nonetheless in the latest U.S Codes such as IBC 2009 [17], ASCE 7 - 10 [18] and AISC 341-10 [19] the definition of seismic zones follows completely different philosophy. These codes cannot be adopted for a region that does not have seismic maps according to the definition of the response spectrum. Hence in Pakistan such modern and recent Codes cannot be commonly used. In is worthy to underline that Eurocode 8 is an advance seismic code and uses the zoning pattern as like UBC 97 therefore could be profitable for the designers to use it as an alternative. Unfortunately less work or no such attempt has been made to motivate the designer to use such code. Therefore, this report is an attempt to draw attention of the designer, technicians and researcher to this aspect of the code. In Eurocode 8 three ductility classes are allowed for the seismic design, i.e. Ductility Class High (DCH), Ductility Class Medium (DCM) and Ductility Class Low (DCL). A flowchart for the use of capacity design rules of Eurocode 8 is also shown in Figure 12. 


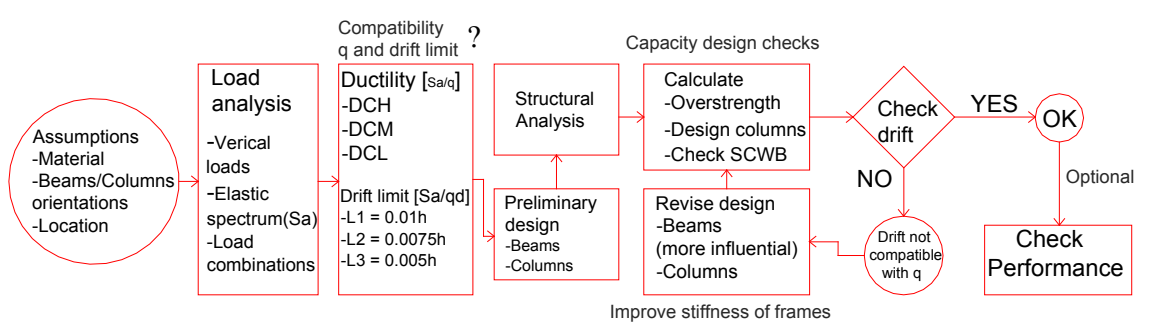

Figure 12. Capacity design flowchart for steel MRF using Eurocodes process.

\subsection{Rigid Frames}

In this section rigid steel frames are discussed which remain elastical or in-elastical depending on the loading conditions. In the case of a low earthquake according to the performance criteria MRFs should be remain in the elastic state. On the other hand for any strong motion earthquake rigid frames might behave in elastically with the condition that it dissipates the seismic energy. Stiffness is affected if MRFs goes into the plastic state. The plastic state of rigid frames in the case of seismic event can be controlled by applying the capacity design rules [13]. The here presented Table 2 shows a synopsis for the capacity design rules for EC3-EC8 (DCH) and AISC-ASCE (SMF).

As moment resisting frames are realized by rigid connections (See Figure 13) therefore guarantees clear opening for therefore offers great flexibility for architectural requirements. Generally the lateral stiffness of steel moment resisting frames is low having excessive deformability and therefore occasionally may allow damage to non-structural elements. Nevertheless due to their high inelastic capabilities the energy dissipation in MRFs is high. If energy dissipation takes place through hysteresis loops at the ends of the beams a ductile collapse mechanism in MRFs is achieved. In this case most convenient collapse distribution foresees by emerging plastic hinges at beam ends and at column bases. This leads to a global mechanism that maximizes the amount of dissipated energy and causes a local ductility demand lower than other collapse mechanisms such as plastic hinges at the column bases. From the capacity design perception, beams are the dissipative elements, whereas connections and columns are non-dissipative elements and must be designed for higher seismic forces to be remain in the elastic state at the level of plasticity in beams ends [20] [21].

In Eurocode 8 the design elastic response spectrum is normally reduced by a behavior factor $(q)$ that equals to 4 for DCM and 6.5 for DCH. Furthermore in order to have a global ductile behavior of the MRFs, beams should be verified in order to have sufficient resistance against lateral torsion buckling in accordance with EN 1993. Beam ends are the fuses in rigid frames and if these are designed properly they perform well. For assuring plastic hinges in the beams, Code gives some supplementary checks for the beams of MRF where demand to capacity due to moment is $100 \%$, due to shear it is $50 \%$ whereas due to axial it is only $15 \%$ as brittle failure is more related to shear and axial. Column are assumed to be elastic as more vulnerable to axial forces specially the compressive 
Table 2. Capacity design rules and drifts limitations.

\begin{tabular}{|c|c|c|}
\hline Description & $E C 8-D C H$ & $A S C E-S M F$ \\
\hline $\begin{array}{l}\text { Restrictions on the use of Cross } \\
\text { section }\end{array}$ & $\begin{array}{l}\text { For } q \text { higher than four only class } 1 \text { sections are } \\
\text { permitted to be used }\end{array}$ & Sections must be compact \\
\hline Seismic load reduction factor & $q$ equal to $5 \alpha_{u} / \alpha_{1}$ & $R$ equal to 8 \\
\hline $\begin{array}{l}\text { Energy dissipation philosophy } \\
\text { (significant inelastic deformation) }\end{array}$ & Given by ductility class high & $\begin{array}{l}\text { Given by special moment resisting frames, and } \\
\text { are anticipated to undergo }\end{array}$ \\
\hline Overstrength factor & $\begin{array}{l}\text { Obtained from ratio of plastic moment of columns to } \\
\text { beams }\end{array}$ & Restricted to 3 \\
\hline Local ductility & Plastic hinge rotation is restricted to $35 \mathrm{mrad}$ & $\begin{array}{l}\text { Plastic hinge rotation is restricted to } 30 \mathrm{mrad} \\
\text { with inter-storey drifts to } 0.04 \text { radians }\end{array}$ \\
\hline Strength checks for Beams & $\frac{M_{E, d}}{M_{p l, R d}} \leq 1.0, \frac{N_{E, d}}{N_{p l, R d}} \leq 0.15, \frac{V_{E, d}}{V_{p l, R d}} \leq 0.5$ & $\begin{array}{l}\text { Only strength checks as per AISC/LRFD are } \\
\text { required }\end{array}$ \\
\hline Ratio & $\frac{q}{\Omega}=?$ & $\frac{R}{\Omega}=\frac{8}{3}=2.67$ \\
\hline $\begin{array}{l}\text { Strong column weak beam (SCWB) } \\
\text { philosophy }\end{array}$ & $\sum M_{R c} \geq 1.3 \sum M_{R b}$ & $\begin{array}{l}\frac{\sum M_{p c}^{*}}{\sum M_{b c}^{*}} \geq 1.0, \text { Columns should have sufficient } \\
\text { flexural strength }\end{array}$ \\
\hline $\begin{array}{l}\text { Non-dissipative members } \\
\text { such as columns }\end{array}$ & $\begin{array}{l}N_{E d}=N_{E d, G}+1.1 \gamma_{o v} \Omega N_{E d, E} M_{E d}=M_{E d, G}+1.1 \gamma_{o v} \Omega M_{E d, E} \\
V_{E d}=V_{E d, G}+1.1 \gamma_{o v} \Omega V_{E d, E}\end{array}$ & $\begin{array}{l}\text { Verification of strength with loads computed } \\
\text { from special load combinations having } \Omega \text { o }\end{array}$ \\
\hline Connections & full strength & full strength \\
\hline
\end{tabular}

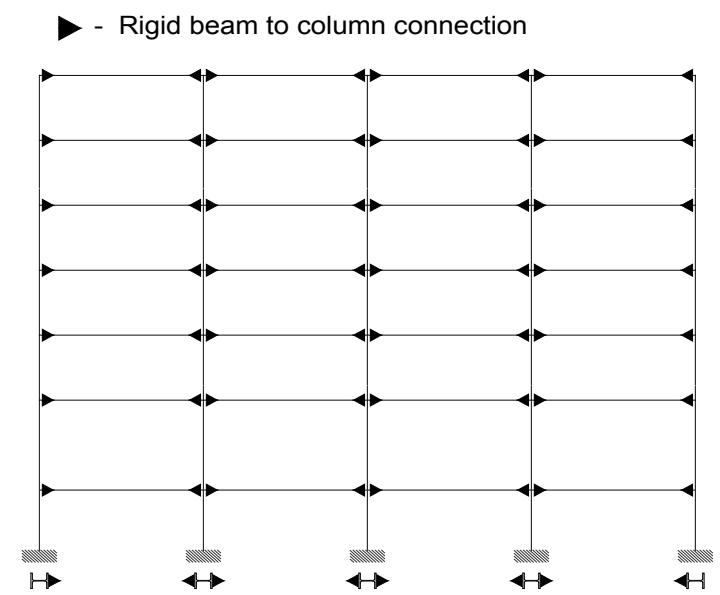

(a)

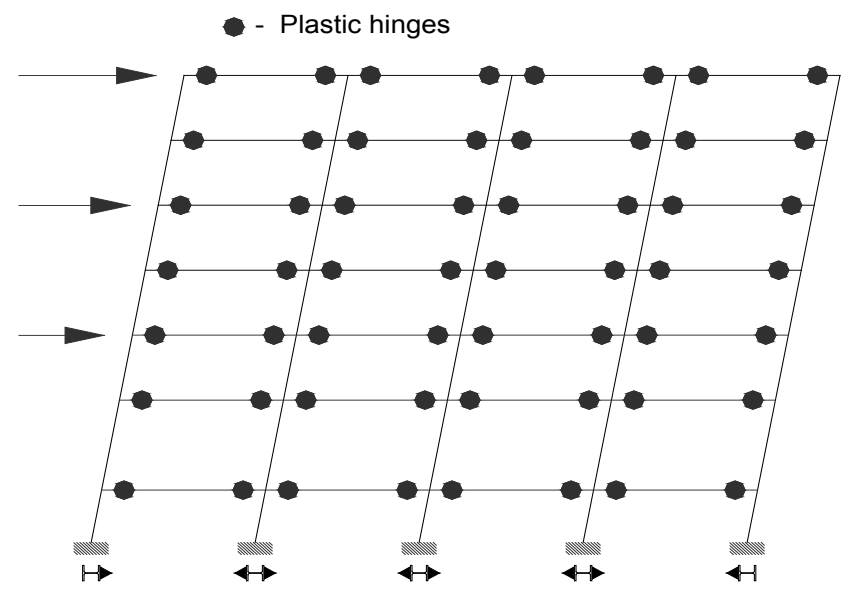

(b)

Figure 13. Moment Resisting Frames: general scheme (a) and global collapse mechanism (b).

ones, therefore the actual seismic forces are increased by overstrength factor. Columns shall be verified in compression considering the most unfavorable combination of the axial force and bending moments. More generally, global ductility is achieved by the implementation of Strong Column Weak Beam "SCWB" philosophy. In this context, Eurocode 8 suggests the condition shown in Equation (9) must be fulfilled at all seismic beam-to-column joints:

$$
\sum M_{R c} \geq 1.3 \sum M_{R b}
$$

The factor 1.3 takes into account the strain hardening and the material over- 
strength which is obtained generally by the multiplication of 1.1 with $\gamma_{o v}$ and as a general rule is considered as 1.3 . Generally this check is often satisfied at the joint when capacity design is employed in the design.

\subsection{Eccentric Braced Frames (EBFs)}

Eccentrically braced frames as shown in Figure 15 are a sort of "compromise" between moment resisting frames and concentrically braced frames. They are conceived for combining the advantages of MRFs in terms of ductility and energy dissipation capacity, with those of CBFs in terms of lateral stiffness. With regard to the architectural flexibility the EBFs solution shows intermediate peculiarities. Therefore the most attractive feature of EBFs for seismic-resistant design is their high stiffness combined with excellent ductility and energy-dissipation capacity. The braces in EBFs deliver the high elastic stiffness characteristic of CBFs, permitting Code drift requirements to be met economically. Additionally under severe earthquakes properly designed and detailed EBFs provide the ductility and energy dissipation capacity characteristic of MRFs [22]. The basic idea is to endow moment resisting frames with appropriate braced members and thus reduce the lateral deformability of the frame. At the same time, since at least one end of the braces is connected to the beams, a part of these, usually called "link", is devoted to the dissipation of the input energy by yielding in shear and/or in flexure as shown by Figure 14 .

In this way the stiffness and ductility properties can be in principle adequately calibrated, so leading towards optimal structural solutions. The performances of the structure are strongly dependent on the behavior of the links, require particular care in the design phase [23]. Eurocode 8 gives simple rules for the design of EBFs where the seismic energy dissipation is taken by vertical or horizontal seismic links. The behavior of link is related to their dimensions and internal forces and therefore three different types of links are defined namely, the short

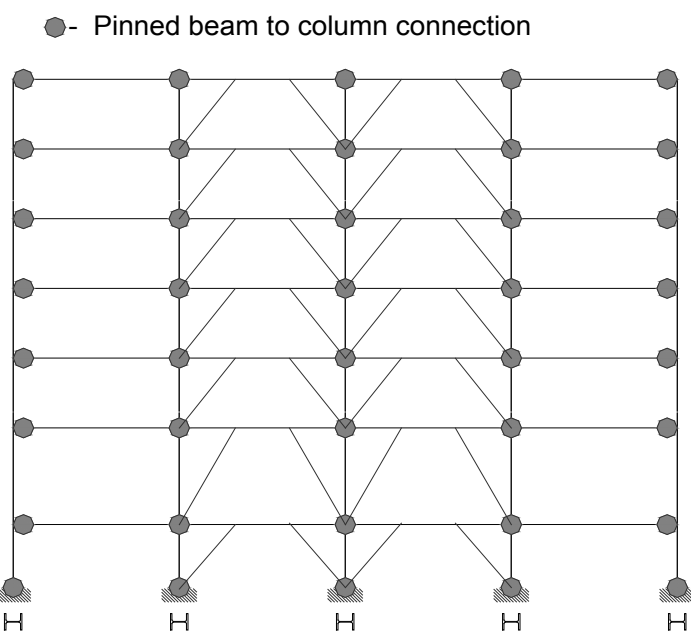

(a)

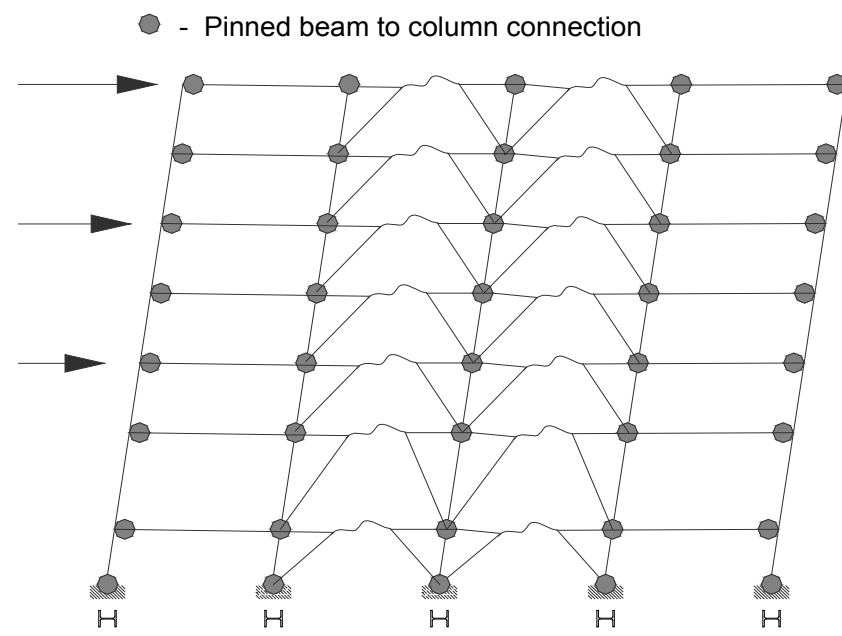

(b)

Figure 14. Eccentrically Braced Frames: general scheme (a) and collapse mechanism (b). 
link (dissipation is guaranteed by yielding in shear), the long link (link dissipate energy by yielding in flexure, see Figure 15(b)) and the intermediate link (where plastic mechanisms is a combination of bending and shear). Figure 15(a) and Figure 15(b) show the Energy W dissipated in plastic mechanisms in shear and in bending. The plastic mechanism achieved in seismic links depends on their length. Short links yield essentially in shear, the energy dissipated in the plastic mechanism is given by Equation (10):

$$
W_{v}=V_{p, l i n k} \times \theta_{p} \times e
$$

Table 3 shows the provisions for Eccentric Braced Frames according to Eurocodes (EC3/EC8) and AISC/ASCE.

The limit between long and short links corresponds to the situation in which yielding could equally take place in shear or bending, therefore Equation (11) explains the case.

$$
W_{v}=W_{M} \Rightarrow V_{p, \text { link }} \times \theta_{p} \times e=2 M_{p, \text { link }} \times \theta_{p} \Rightarrow e=2 \times\left(\frac{M_{p, \text { link }}}{V_{p, \text { link }}}\right)
$$

For values of $e$ around this limit, significant bending moments and shear forces exist simultaneously and their interaction has to be considered. In Eurocode 8 , the value of $e$ for considering a plastic mechanism in shear (short links) is given by Equation (12).

$$
e<e_{s}=1.6 \times\left(\frac{M_{p, \text { link }}}{V_{p, \text { link }}}\right)
$$

The value of e for considering only a plastic mechanism in bending (long links) is calculated using Equation (13).

$$
e<e_{L}=3 \times\left(\frac{M_{p, \text { link }}}{V_{p, \text { link }}}\right)
$$

Between these two values $e_{s}$ and $e_{L}$, links are said to be "intermediate" and the interaction between shear and bending has to be considered. If the typology of the structure is such that the shear and bending moment diagrams are not symmetrical, only one plastic hinge will form if the link is long, therefore Equation (14) takes place.

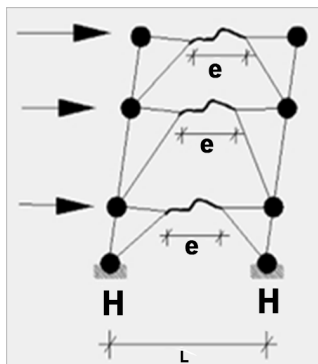

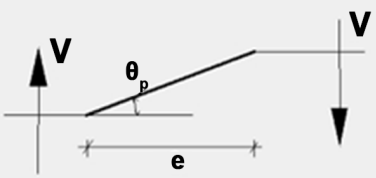

$\mathbf{W}_{\mathrm{v}}=\mathbf{V}_{\mathrm{pl}, \text { link }} \theta$ pe

(a)

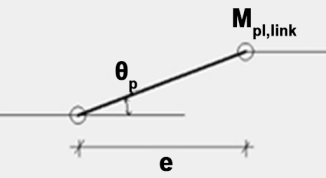

$\mathbf{W}_{\mathbf{M}}=\mathbf{M}_{\mathrm{pl}, \text { link }} \boldsymbol{\theta}_{\mathrm{p}}$

(b)

Figure 15. Energy W dissipated in Plastic Mechanisms a) in Shear b) in Bending. 
Table 3. Provisions for eccentric braced frames.

\begin{tabular}{|c|c|c|c|}
\hline Description & Eurocodes (EC3/EC8) & AISC/ASCE & Remarks \\
\hline $\begin{array}{l}\text { Energy dissipation } \\
\text { philosophy }\end{array}$ & $\begin{array}{l}\text { EBFs shall be designed so that specific } \\
\text { elements or parts of elements called } \\
\text { seismic links are able to dissipate energy } \\
\text { by the formation of plastic bending } \\
\text { and/or plastic shear mechanisms. }\end{array}$ & $\begin{array}{l}\text { EBFs are expected to withstand } \\
\text { significant inelastic deformations in the } \\
\text { links when subjected to the forces } \\
\text { resulting from the motions of the design } \\
\text { earthquake. }\end{array}$ & An almost same criterion is considered \\
\hline $\begin{array}{l}\text { Rotation capacity } \\
\text { (local ductility } \\
\text { concept) }\end{array}$ & $\begin{array}{l}\text { Plastic hinge rotation is limited to } 35 \\
\text { mrad for structures of DCH and } 25 \\
\text { mrad for structures of DCM }\end{array}$ & $\begin{array}{l}\text { Link rotation angle shall not exceed (a) } \\
0.08 \text { radians for links of length } 1.6 \\
M_{p} / V_{p} \text { or less and (b) } 0.02 \text { radians for } \\
\text { links of length } 2.6 M_{p} / V_{p} \text { or greater. }\end{array}$ & $\begin{array}{l}\text { For high seismicity it is recommended } \\
\text { by both codes to apply ductility concept }\end{array}$ \\
\hline $\begin{array}{l}\text { Dissipative } \\
\text { members }\end{array}$ & $\begin{array}{l}\text { Plastic Hinges should take place in links } \\
\text { prior to yielding or failure elsewhere. }\end{array}$ & $\begin{array}{l}\text { EBFs are expected to withstand } \\
\text { significant in-elastic deformations in the } \\
\text { links when subjected to forces resulting } \\
\text { from the motions of the design } \\
\text { earthquake. }\end{array}$ & $\begin{array}{l}\text { Links can be short, long and } \\
\text { Intermediate. Which fail due to Shear, } \\
\text { bending and bending \& Shear } \\
\text { respectively. }\end{array}$ \\
\hline $\begin{array}{l}\text { If } \\
N_{E D} / N_{p l, R d} \leq 0.15 \\
\text { then Check for } \\
\text { Design Resistance } \\
\text { of Link is }\end{array}$ & $\begin{array}{l}V_{E D} \leq V_{p, \text { link }} \\
M_{E D} \leq M_{p, \text { link }}\end{array}$ & $\begin{array}{l}\text { Effect of axial force on the link, available } \\
\text { shear strength need not be considered if } \\
P_{u} \leq 0.15 P_{y} \text { (LRFD) or } \\
P_{a} \leq 0.15 / 1.5 P_{y} \text { (ASD) }\end{array}$ & $\begin{array}{l}N_{E D}, M_{E D} \& V_{E D} \text { respectively are the } \\
\text { design axial force, design bending } \\
\text { moment and design shear at both ends } \\
\text { of the link. }\end{array}$ \\
\hline $\begin{array}{l}\text { Check to achieve } \\
\text { global dissipative } \\
\text { behaviour of the } \\
\text { structure }\end{array}$ & $\begin{array}{l}\text { The maximum overstrength } \Omega_{i} \text { should } \\
\text { not differ from the minimum value } \Omega \text { by } \\
\text { more than } 25 \%\end{array}$ & $\begin{array}{l}\text { The required strength of each lateral } \\
\text { brace at the ends of the link shall be } \\
P_{b}=0.06 M_{r} / h_{0} \text {, where } h_{0} \text { is the } \\
\text { distance flange centroids }\end{array}$ & $\begin{array}{l}\Omega_{i}=1.5 V_{p, \text { link }, i} / V_{E D, i} \text { among all short } \\
\text { links and minimum value of } \\
\Omega_{i}=1.5 M_{p, \text { link }, i} / M_{E D, i} \text { among all } \\
\text { intermediate and long links. }\end{array}$ \\
\hline $\begin{array}{l}\text { Seismic load } \\
\text { reduction factor }\end{array}$ & $\begin{array}{l}\text { A behaviour factor }(q) \text { equal to } 4 \text { for } \\
\text { DCM and } 5 \alpha_{u} / \alpha_{1} \text { for } \mathrm{DCH} \text { is provided. } \\
\text { the minimum value of } \\
\Omega_{i}=1.5 V_{p, l i n k, i} / V_{E D, i} \text { among all short }\end{array}$ & $\begin{array}{l}\text { A response modification factor }(R) \text { equal } \\
\text { to } 8.0 \text { for EBFs is given }\end{array}$ & An almost same criterion is considered \\
\hline Overstrength factor & $\begin{array}{l}\text { links, whereas } \\
\text { the minimum value of } \\
\Omega_{i}=1.5 M_{p, l i n k, i} / M_{E D, i} \text { among all } \\
\text { intermediate and long links; }\end{array}$ & $\Omega_{\mathrm{o}}$ equal to 2 for EBFs is given & $\Omega_{\mathrm{o}}$ in EC8 is $\left(1.1 \gamma_{o r} \Omega\right)$ \\
\hline
\end{tabular}

$$
W_{M}=M_{p, \text { link }} \times \theta_{p}
$$

In this case, the limiting length between long and short links corresponds to Equation (15).

$$
\Rightarrow e=\left(\frac{M_{p, \text { link }}}{V_{p, \text { link }}}\right)
$$

The following rules are allowed by Eurocode 8:

1) The reduction of the elastic design spectrum through a behavior factor $(q)$ equals to 4 for DCM and 6.5 for DCH; 2) The web of the link should not be reinforced with plate, 3 ) In cases, when Equation (16) holds.

$$
\frac{N_{E d}}{N_{P l, R d}} \leq 0.15
$$

In cases, when Equation (17) is satisfied.

$$
\frac{N_{E d}}{N_{P l, R d}}>0.15
$$


Then plastic shear and moment should be reduced by the effect of axial forces in the bracings.

The recommended inelastic rotation limits for different link lengths without restriction on the configuration of the link are; 0.08 radians or 4.6 for Short links, 0.02 radians or $1.15^{\circ}$ for Long links and for Intermediate links the value is determined by linear interpolation. The criteria that must be satisfied in order to form a global plastic mechanism are similar in frames with eccentric or concentric braces, because they correspond to the same concept. Further, there should be homogenization of the dissipative connections overstrength $\Omega_{i}$ over the height of the building for short and long links is calculated using Equation (18) and Equation (19), respectively:

$$
\begin{gathered}
\text { Short links: } \Omega_{i}=1.5\left(\frac{V_{p l, R d, i}}{V_{E d, i}}\right) \\
\text { Long links: } \Omega_{i}=1.5\left(\frac{M_{p l, R d, i}}{M_{E d, i}}\right)
\end{gathered}
$$

The minimum value of $\Omega_{i}$ should be used in the design, further the maximum value of $\Omega_{i}$ should not differ from the minimum by more than $25 \%$. $\Omega_{i}$ will ensure that yielding occurs simultaneously at several places over the height of the building, and a global mechanism is formed. The beams, columns, and connections are "capacity designed" relative to the real strengths of the seismic links.

\subsection{Concentric Braced Frames (CBFs)}

One of the main concern of steel MRFs is their high susceptibility to large lateral displacements (lateral stiffness) during severe earthquakes, therefore needs special attention while designing. In order to limit interstorey drift, the issues due to geometric nonlinearities and brittle fracture of beam-to-column connections are mitigated and therefore excessive damage to non-structural elements is avoided. Therefore as an alternative, to many practical and economic issues involved, engineers are increasingly turning to the use of concentrically braced steel frames as a structure's lateral load resisting system. Steel concentrically braced frames are assumed and recommended to be strong, stiff and ductile. The quality of the seismic response of these frames is determined by the performance of the brace. For achieving a good performance in cross bracing system the brace must behave as a structural fuse thus should fail prior to any other component of the frame. This is important because although the frame may sustain significant damage during an earthquake, it is expected to remain stable and the building must be capable of resisting gravity loads and withstanding aftershocks without collapse.

Concentrically braced frames as shown in Figure 13 are made of structural members which, from a theoretical point of view, may be connected each other by means of simple flexural hinges. The resistance to horizontal forces is achieved by means of temporary braces, which essentially work in tension or 
compression. From an architectural point of view, the meshes of the frame which are occupied by the braces cannot be used for openings, with consequent functional flexibility reduction. The initial lateral stiffness of CBFs is generally high, due to the axial stiffness of the braces. On the other hand, the capacity of dissipating the input seismic energy is quite poor, it being based on the plasticization of braces in tension. The effectiveness of this dissipation mechanism is reduced cycle by cycle, due to the degradation caused by the repeated buckling undergone when braces are subjected to compression (see Figure 16). From the capacity design point of view, the dissipative elements are the braces, whereas the connections, the beams and the columns must be over-resistant, behaving in the elastic field up to the failure of the braces [24].

A similar approach like the one for MRFs is defined by Eurocode 8 for concentric braced frames. In this case it is aimed to obtain a ductile behavior by imposing that the yielding of diagonal members occurs before premature failure of beams, columns and connections (capacity design approach) [23] [25] [26]. In order to obtain such strength hierarchy among the structural members, Eurocode 8 [13] provides a simplified design procedure. This approach begins from a linear analysis of $\mathrm{CBF}$ structure under reduced seismic loads. With reference to frames with cross bracing (X-CBF) the simplified procedure involves the following assumptions, limitations and checks: a) the reduction of the elastic design spectrum through a behavior factor (q) equals to 4 for both DCM and DCH (See Figure 17); b) the use of a scheme with tension-only diagonals for the evaluation of the design axial forces in the braced frames members (Figure 18); c) a maximum allowable value for the non-dimensional slenderness $\bar{\lambda}$ of diagonals is given as $\bar{\lambda} \leq 2.0$.

$\bar{\lambda} \leq 2.0$ is used to ensure satisfactory behavior under cyclic loading, where $\bar{\lambda}$ is defined as the square root of the ratio between the plastic resistance $N_{p l, R d}$ and the Eulerian buckling load $N_{c r}$ of the diagonal.

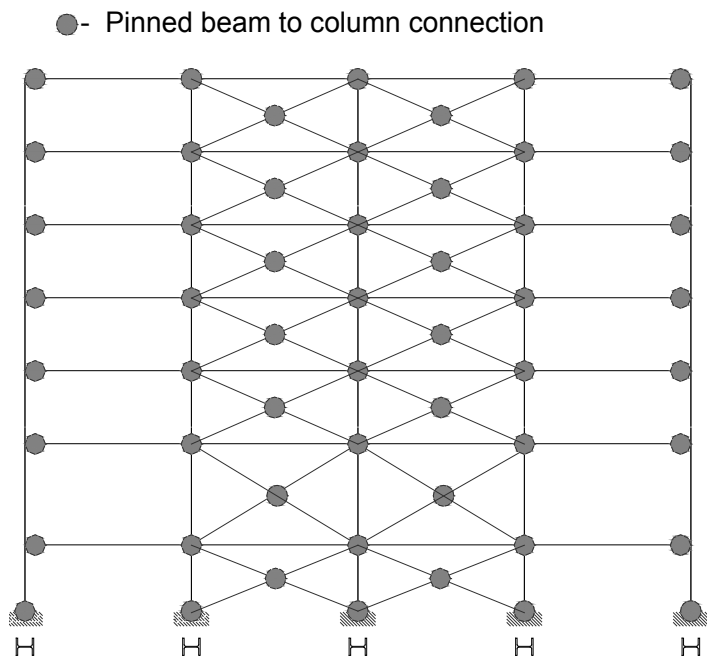

(a)

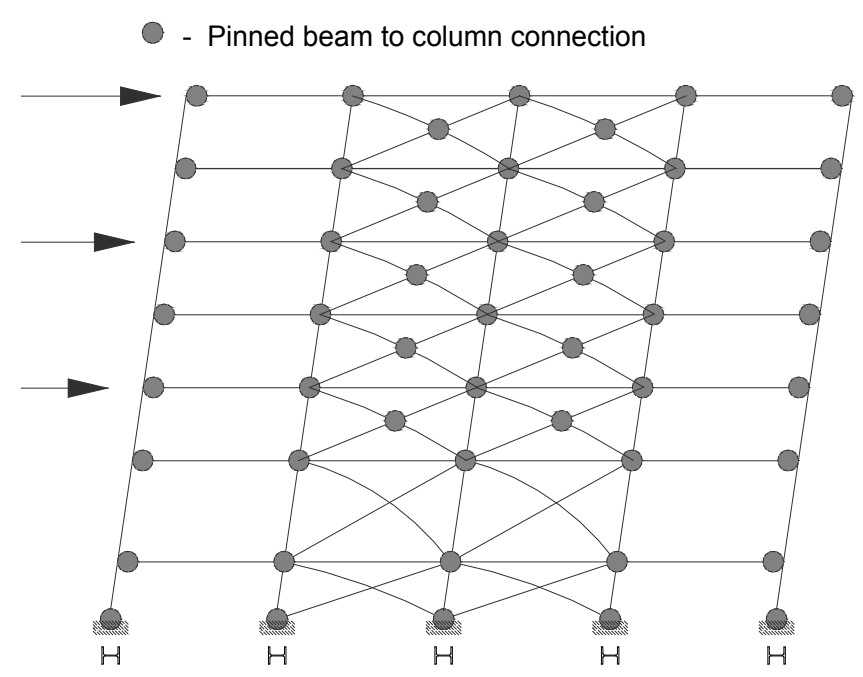

(b)

Figure 16. Concentrically Braced Frames: (a) general scheme; (b) collapse Mechanism. 


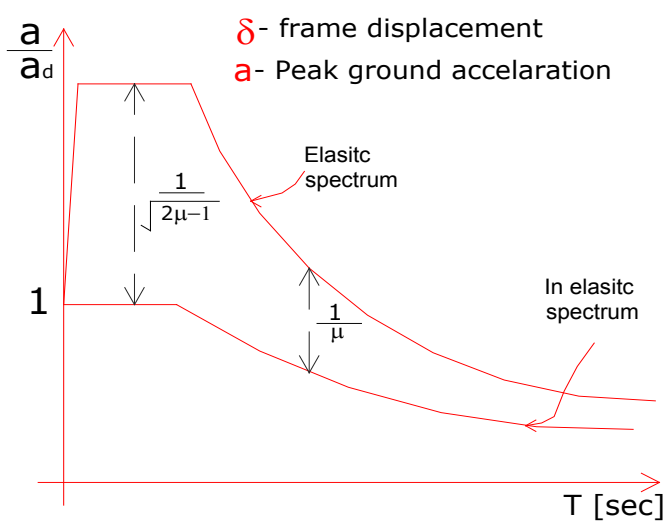

Figure 17. Reduction of the elastic spectrum (Eurocode 8 spectrum [13]).

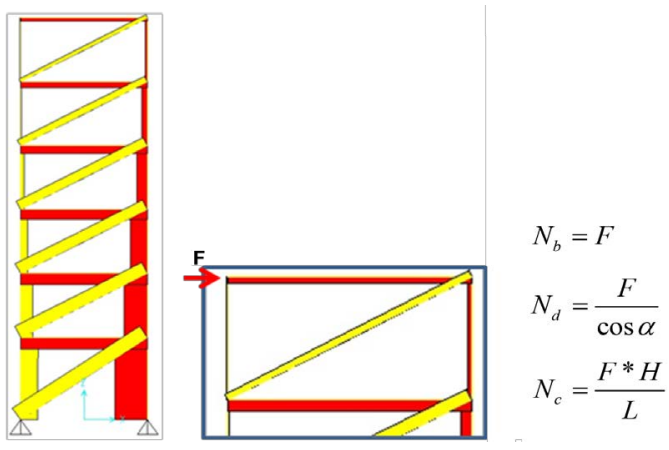

Figure 18. Axial forces in diagonal and column: Tension only model.

d) A minimum allowable value for the non-dimensional slenderness $\bar{\lambda}$ of diagonals is given by $\bar{\lambda}>1.3$.

e) In the case of cross bracing configurations (X-CBFs), devoted to avoid overloading of columns in the pre-buckling stage of compressed diagonal, i.e. when the actual structural scheme is the Tension/Compression one; where $\Omega_{i}$ is the diagonal overstrength coefficient for the $i^{\text {th }}$ diagonal members of the considered braced frame, defined as the axial strength capacity to demand ratio, given by Equation (20).

$$
\Omega_{i}=\left(\frac{N_{p l, R d, i}}{N_{E d, i}}\right)
$$

A maximum allowable value for the difference between the maximum $\left(\Omega_{\max }\right)$ and the minimum $\left(\Omega_{\min }\right)$ values of the diagonal overstrength coefficients $\Omega_{p}$ according to Equation (21).

$$
\frac{\Omega_{\max }}{\Omega_{\min }} \leq 1.25
$$

Equation (21) is devoted to obtain a uniform distribution of plastic demand along the building height, thus reducing the potential for damage concentration and eventual soft-storey mechanisms; 
f) The amplification of design axial forces in beam and columns (non-dissipative elements) through the system overstrength factor $\Omega$.

\section{Conclusion}

The paper has dealt initially with the importance of seismic codes in general and particularly in Pakistan. From past earthquakes for example Quetta 1935, it is revealed that steel structures performed well within the limited use of steel frame structures; nevertheless their trend is still not so common in Pakistan. Useful and important steel structures have been constructed before the independence of Pakistan as mentioned in this paper. Furthermore, the use of most advance code such as Eurocode $\mathbf{8}$ is convenient to be used in the country as the defined spectrum of the code is based on the seismic zonation which is presently available for all the regions of the country. Common parameters that are normally adopted by seismic codes are given and the importance of over-strength factor especially the elastic one that was highlighted gives a clear understanding for the designer involved in the seismic design of structures. In addition, conventional seismic load resisting systems were illustrated and their design criteria according to Eurocode 8 were provided with synoptic tables for the counterpart US code. The procedure of Eurocode 8 is explained through the use of capacity design approach in which it is evident that the calculation of overstrength required some steps and iterations whereas in the US codes this factor is generally fixed for all the lateral load resisting systems. In addition, the behavior factor in Eurocode is less compared to the suggested value of response modification factor in the US codes. Furthermore, it is to be underline that the capacity design rule of Eurocode 8 requires some iteration as calculation of overstrength factor is involved and this becomes more complex when the deformability needs to be satisfied. It is believed and concluded that the lateral load resisting systems that dissipate more seismic energy are of prime importance and therefore need attention to be incorporated in the plastic design.

\section{References}

[1] Building Code of Pakistan (BCP) (2007) Building Code of Pakistan (Seismic Provisions-2007). In: Ministry of Housing and Works, Ed., Pakistan Engineering Council, Islamabad.

[2] UBC-1997 (1997) International Conference of Building Officials. ed. Whittier, California.

[3] Naqash, M.T. (2012) Optimum Design of Steel Moment Resisting Frames Using Eurocode 8. Doctorate PhD Thesis, Department of Engineering and Geology (Ph.D. Thesis), University of Chiete and Pescara, Pescara.

[4] Naqash, M.T. (2014) Study on the Fundamental Period of Vibration of Steel Moment Resisting Frames. International Journal of Advanced Structures and Geotechnical Engineering, 3, 01-06.

[5] Kumar, S.L. (1933) Theory of Earthquake Resisting Design with a Note on Earthquake Resisting Construction in Baluchistan. Punjab Enginering Congress.

[6] Naqash, M.T. and Umar, F.Q. (2018) Performance of Rigid Steel Frames under 
Adequate Soil Conditions Using Seismic Code Provisions. Open Journal of Civil Engineering, 8, 1-12. https://doi.org/10.4236/ojce.2018.82008

[7] Alvi, P.M. (2011) The Bridges of Pakistan. http://pakistaniat.com/2011/03/11/pakistan-bridges/

[8] Miranda, E. and Bertero, V.V. (1994) Evaluation of Strength Reduction Factors for Earthquake-Resistant Design. Earthquake Spectra, 10, 357-357. https://doi.org/10.1193/1.1585778

[9] Fajfar, P. (2000) A Nonlinear Analysis Method for Performance-Based Seismic Design. Earthquake Spectra, 16, 573-592. https://doi.org/10.1193/1.1586128

[10] SEAOC Seismology Committee (2008) A Brief Guide to Seismic Design Factors. STRUCTURE.

http://www.structuremag.org/Archives/2008-9/C-GuestCol-SeismicDesign-SEAOC -Sept08.pdf

[11] Naqash, M.T. (2017) Codal Comparisons for the Seismic Resistance of Steel Moment Resisting Frames (MRF). Part A: Codes Approach. International Journal of Construction Engineering and Management, 6, 254-263.

[12] Naqash, M.T. (2017) Codal Comparisons for the Seismic Resistance of Steel Moment Resisting Frames (MRFs). Part B: Design Approach. International Journal of Construction Engineering and Management, 6, 264-272.

[13] EN-1998-1 (2005) Eurocode 8, Design of Structures for Earthquake Resistance, Part 1: General Rules, Seismic Actions and Rules for Buildings. In: CEN, Ed., European Committee for Standardization, 36 B-1050, Brussels.

[14] Gioncu, V. and Mazzolani, F.M. (2002) Ductility of Seismic Resistant Steel Structures. Vol. 1, Taylor \& Francis, Milton Park, Abingdon-on-Thames.

[15] Naeim, F. (1989) The Seismic Design Handbook. Springer, Berlin.

[16] Brescia, M. (2008) Rotation Capacity and over Strength of Steel Members for Seismic Design. UNINA.

[17] Code, I.B. (2009) International Building Code 2009 (IBC-2009). International Code Council.

[18] ASCE/SEI-7-10 (2010) Minimum Design Loads for Buildings and Other Structures. American Society of Civil Engineers, Virginia.

[19] ANSI/AISC-341-10 (2010) Seismic Provisions for Structural Steel Buildings. American Institute of Steel Construction, Chicago.

[20] Adan, S.M. and Hamburger, R.O. (2010) Steel Special Moment Frames Structure. http://www.structuremag.org/?p=4884

[21] Bungale, S.T. (2005) Wind and Earthquake Resistant Buildings Structural Analysis and Design. Marcel Dekker, $892 \mathrm{p}$.

[22] Roeder, C.W. and Popov, E.P. (1977) Inelastic Behavior of Eccentrically Braced Steel Frames under Cyclic Loadings. NASA STI/Recon Technical Report N, Vol. 78, 20375.

[23] Brandonisio, G., et al. (2012) Seismic Design of Concentric Braced Frames. Journal of Constructional Steel Research, 78, 22-37.

[24] Uriz, P. and Mahin, S.A. (2004) Seismic Performance Assessment of Concentrically Braced Steel Frames. Proceedings of the 13th World Conference on Earthquake Engineering, Vancouver, 1-6 August 2004, 6.

[25] Naqash, M.T. (2016) Effect of Interstorey Drift Limits on High Ductility in Seismic Design of Steel Moment Resisting Frames. Pakistan Journal of Engineering and Ap- 
plied Sciences, 16, 133-142.

[26] Naqash, M.T., et al. (2014) An Overview on the Seismic Design of Braced Frames. American Journal of Civil Engineering, 2, 41-47.

https://doi.org/10.11648/j.ajce.20140202.15 


\section{Nomenclature}

$q_{\mu, \rho}:$ Ductility reduction factor

$V_{e}:$ Elastic base shear

$V_{\dot{y}}$ Base shear obtained at the arrival of first plastic hinge

$\Omega_{\rho}$ : Redundancy factor

$V_{u}:$ Ultimate base shear

$\Omega_{E}:$ Elastic overstrength factor

$V_{\dot{d}}$ : Design base shear calculated from the prescribed Code

$\Omega_{E,,}$ : Global overstrength factor

$q_{\mu}$ : Reserve ductility

$R$ : Response modification factor

$q$ : Behaviour factor

$\alpha_{u}$ : Multiplier of horizontal seismic design action at formation of global plastic mechanism

$\alpha_{1}$ : Multiplier of horizontal design seismic action at formation of first plastic hinge in the system

$\gamma_{c}$ Partial factor for concrete

$\gamma_{R \dot{ }}$ : Model uncertainty factor on design value of resistances in the estimation of capacity design action effects, accounting for various sources of overstrength

$\gamma_{s}$ : Partial factor for steel

$M_{E \dot{d}}$ Design bending moment from the analysis for the seismic design situation

$M_{p l, R d A}:$ Design value of plastic moment resistance at end A of a member

$M_{p l, R d B}$ : Design value of plastic moment resistance at end $\mathrm{B}$ of a member

$V_{E d, i}, M_{E d, i}$ : Design values of the shear force and of the bending moment in Link $i$ in the seismic design situation

$V_{p, \text { link }, i} M_{p, \text { link }, i}$ Shear and bending plastic design resistances of link $i$

$\Sigma M_{R c}$ and $M_{R b}$ : Sum of the design values of the moments of resistance framing the joint of the columns and beams respectively

$N_{E \dot{d}}$ Design axial force from the analysis for the seismic design situation

$V_{E \dot{d}}$ Design shear force from the analysis for the seismic design situation

$N_{E d, E}$ : Axial force from the analysis due to the design seismic action alone

$N_{E d, G}$ Axial force due to the non-seismic actions included in the combination of actions for the seismic design situation

$N_{p l, R d}$ design value of yield resistance in tension of the gross cross-section of a member

$V_{p l, R \dot{d}}$. Design value of shear resistance of a member

$N_{R d}\left(M_{E d} V_{E d}\right)$ : Design value of axial resistance of column or diagonal taking into account the interaction with the bending moment $M_{E d}$ and the shear $V_{E d}$ in the seismic situation

$\Omega$ : Multiplicative factor on axial force $N_{E d, E}$ from the analysis due to the design seismic action, for the design of the non-dissipative members in concentric or eccentric braced frames 